\title{
Oil price uncertainty and movements in the US Government bond risk premia
}

\section{Article}

\section{Accepted Version}

Creative Commons: Attribution-Noncommercial-No Derivative Works 4.0

Balcilar, M., Gupta, R., Wang, S. and Wohar, M. E. (2020) Oil price uncertainty and movements in the US Government bond risk premia. North American Journal of Economics and Finance, 52. 101147. ISSN 1062-9408 doi:

https://doi.org/10.1016/j.najef.2020.101147 Available at https://centaur.reading.ac.uk/88485/

It is advisable to refer to the publisher's version if you intend to cite from the work. See Guidance on citing.

To link to this article DOI: http://dx.doi.org/10.1016/j.najef.2020.101147

Publisher: Elsevier

All outputs in CentAUR are protected by Intellectual Property Rights law, including copyright law. Copyright and IPR is retained by the creators or other copyright holders. Terms and conditions for use of this material are defined in the End User Agreement.

\section{www.reading.ac.uk/centaur}

\section{CentAUR}

Central Archive at the University of Reading 
Reading's research outputs online 


\title{
Oil Price Uncertainty and Movements in the US Government Bond Risk Premia ${ }^{\#}$
}

\begin{abstract}
In this paper, we analyze the predictability of the movements of bond premia of US Treasury due to oil price uncertainty over the monthly period 1953:06 to 2016:12. For our purpose, we use a higher order nonparametric causality-in-quantiles framework, which in turn, allows us to test for predictability over the entire conditional distribution of not only bond returns, but also its volatility, by controlling for misspecification due to uncaptured nonlinearity and structural breaks, which we show to exist in our data. We find that oil uncertainty not only predicts (increases) US bond returns, but also its volatility, with the effect on the latter being stronger. In addition, oil uncertainty tends to have a stronger impact on the shortest and longest maturities (2- and 5-year), and relatively weaker impact on bonds with medium-term (3- and 4-year) maturities. Our results are robust to alternative measures of oil market uncertainty and bond market volatility.
\end{abstract}

Keywords: Oil Price Uncertainty, Bond Returns and Volatility; Higher-Order Nonparametric Causality-in-Quantiles Test

JEL Codes: C22, G12, Q02

\footnotetext{
\# We would like to thank two anonymous referees for many helpful comments. However, any remaining errors are solely ours.
} 


\section{Introduction}

The theories of investment under uncertainty and real options predict that uncertainty about, for example, oil prices will induce optimizing firms to postpone investment decisions, thereby leading to a decline in aggregate output (Bernanke, 1983). Empirical evidence in favour of this line of reasoning for the economy of the United States (US) can be found in the works of Elder and Serletis $(2010,2011)$ (and also verified globally more recently by van Eyden et al., (2019)). Given that oil price uncertainty negatively affects macroeconomic variables (Bams et al., 2017), shows that oil market uncertainty also predicts valuation of stocks in the US. ${ }^{1}$

Against this backdrop, the objective of our study is to analyse the role of oil price uncertainty in predicting movements of risk premia (excess returns) of U.S. government bonds. This is an important question since accurate prediction of interest rate movements are important to bond investors and policymakers. While for central bankers, understanding the evolution of future interest rates help in the fine tuning of monetary policies, for bond market investors, correct prediction of interest rates is likely to result in higher bond returns performance. For our purpose, following Balcilar et al., (2018), we use the higher ( $k$-th) order nonparametric causality-in-quantiles approach, which in turn, allows us to test for predictability over the entire conditional distributions of both bond returns and volatility simultaneously by controlling for misspecification due to uncaptured nonlinearity. Since we are dealing with uncertainty (in the oil market), we believe that it is likely to have not only an impact on the first-moment, but also the second moment of bond premia - a reasoning in line with recent studies (see for example, Buraschi et al., 2014; Balcilar et al., 2016; Chuliá et al., 2017), which depicts the impact of overall macroeconomic uncertainty on not only returns of financial (bonds, currencies and equities) markets, but also volatility.

At this stage, it is important to discuss the channels through which oil market uncertainty is likely to affect excess bond returns and its volatility. As discussed above, oil price uncertainty tends to have a recessionary impact on the economy, and hence, agents in the economy would need to be compensated for holding bonds with longer maturities, which are riskier. In other words during phases of a weaker uncertain economy, premium on assets would increase (Pástor and Veronesi, 2012). Moreover, given the recent financialization of the commodity sector, the oil market is now also considered as a profitable alternative investment in the portfolio decisions (Bahloul, 2018), and hence portfolio reallocations are likely to have feedback from the oil market uncertainty to the bond market risk i.e., volatility (Tiwari et al., 2018). In other words, oil market uncertainty is likely to affect the first and second moment movements of bond markets (as well as other asset markets).

There is of course a large number of studies on predicting risk premia of U.S. government bonds (e.g., Cochrane and Piazzesi (2005), Cooper and Priestly (2009), Ludvigson and Ng (2009, 2011), Laborda and Olmo (2014), Zhu (2015), Ghysels et al., (2018), Çepni et al., (2019a, b, forthcoming), Gargano et al., (2019)). ${ }^{2}$ But, these studies highlight the role of macro and financial (often extracted from large data sets), and behavioral factors in predicting (excess) bond returns, over and above the so-called "CP" factor of Cochrane and Piazzesi

\footnotetext{
${ }^{1}$ Earlier, Elyasiani et al., (2011) shows, using US sectoral data, that oil futures return volatility influences excess returns of oil user industries. In addition, the studies of Choi and Hammoudeh (2010), Kang et al., (2015a, b), and Salisu and Oloko (2015) indicate significant spillover from oil market volatility on US stock returns and volatility. ${ }^{2}$ Important earlier studies are Keim and Stambaugh (1986), Fama and Bliss (1987), Fama and French (1989), and Campbell and Shiller (1991).
} 
(2005), which in turn is a linear combination of five forward spreads. To the best of our knowledge, this is the first paper that evaluates the predictive power of oil price uncertainty for US bond returns and volatility based on a nonparametric causality-in-quantiles framework over the monthly period of 1953:06 to 2016:12.

At this juncture, it must be emphasized that the need to use the $k$-th order nonparametric causality-in-quantiles test emanates from the need to appropriately model the features in the data and hence, provide reliable inferences for not only the first, but also the second moment of excess bond returns (Nishiyama et al., 2011; Jeong et al., 2012; Balcilar et al., 2018). The causality-in-quantile approach has the following three novelties: Firstly, it is robust to misspecification errors as it detects the underlying dependence structure between the examined time series in a data-driven nonparametric manner, which could prove to be particularly important as it is well known that US bond (asset) markets display nonlinear dynamics (Guidolin et al., 2009) - a fact we show below as well. Secondly, via this methodology, we are able to test not only for causality-in-mean (1st moment), but also for causality that may exist in the tails of the joint distribution of the variables, which in turn, is important if the dependent variable has fat-tails - something we show below to hold for the bond premia of various maturities. Finally, we are also able to investigate causality-in-variance and, thus, study higherorder dependency. Such an investigation is important because, during some periods, causality in the conditional-mean may not exist while, at the same time, higher-order interdependencies may turn out to be significant.

The lack of studies analysing the impact of oil price movements on the US bond market is quite puzzling, given the well-established importance US Treasury securities as a global safe haven (Kopyl and Lee, 2016; Habib and Stracca, 2017; Hager, 2017), and also the fact that the bond market in 2018 was valued at more than $\$ 40$ trillion US dollars, which in turn was \$10 trillion US dollars more than the corresponding capitalization of the stock market (Bloomberg). While the existing international literature on the price, returns, and volatility relationship between oil and equity markets is huge to say the least (see for example, Degiannakis et al., (2018), and Smyth and Narayan (2018) for detailed reviews in this regard), in comparison, the number of studies examining the causal linkage between the bond and oil markets, is negligible.

Concerning the sparse literature, Kang et al., (2014) utilized a structural vector autoregressive model to investigate how the demand and supply shocks driving the global crude oil market affect real bond returns of the US. They found that a positive oil market-specific demand shock is associated with significant decreases in real returns of an aggregate bond index for 8 months following the shock. Bouri et al., $(2017,2018,2019)$ provided evidence of the impact of commodity and oil market uncertainty on volatility of sovereign risks of emerging and frontier countries, while Shahzad et al., (2017) did the same on the levels of sovereign credit default swap (CDS) spreads of GCC and oil-exporting countries. Gormus et al., (2018), while dealing with price transmission tests of high-yield bond market, which account for gradual structural shifts, suggested significant impact from oil and ethanol prices. Similarly, Apergis (2019) explored the potential impact of oil prices on high-yield corporate bond spreads for the case of European non-energy and energy corporate samples from 14 countries and spans the period from 2000-2016. The findings document the presence of a positive link between oil prices and the high-yield spreads in the case of non-energy firms and a negative link between oil prices and the high-yield spreads in the case of energy firms. Finally, based on volatility tests, they found uni-directional volatility transmission from energy markets to the high-yield bond market. In the context of investment bonds, Wan and Kao (2015) found that positive shocks in oil the spreads between the AAA and BAA rated bonds. 
As can be seen from the above discussion, barring the somewhat related work of Kang et al., (2014) in terms of dealing with oil shocks and the US bond market, none of the existing studies have analyzed the US Treasuries. More importantly, no paper has so far dealt with the question of impact of oil price uncertainty on the excess returns and volatility of US government bonds of various maturities based on a nonparametric causality-in-quantiles test. The remainder of the paper is organized as follows: Section 2 outlines the methodology, while Section 3 discusses the data and econometric results. Section 4 conducts several robustness checks, with Section 5 concluding the paper.

\section{Econometric Methodology}

In this section, we briefly describe the methodology for testing nonlinear causality via a hybrid approach used in Balcilar et al., (2018), which is based on the frameworks of Nishiyama et al., (2011) and Jeong et al., (2012). Let $y_{t}$ denote excess bond returns and $x_{t}$ the oil market uncertainty.

$x_{t}$ does not cause $y_{t}$ in the $\theta$-th quantile with respect to $\left\{y_{t-1}, \ldots, y_{t-p}, x_{t-1}, \ldots, x_{t-p}\right\}$ if

$$
Q_{\theta}\left(y_{t} \mid y_{t-1}, \ldots, y_{t-p}, x_{t-1}, \ldots, x_{t-p}\right)=Q_{\theta}\left(y_{t} \mid y_{t-1}, \ldots, y_{t-p}\right)
$$

$x_{t}$ is a prima facie cause of $y_{t}$ in the $\theta$-th quantile with respect to $\left\{y_{t-1}, \ldots, y_{t-p}, x_{t-1}, \ldots, x_{t-p}\right\}$ if

$$
Q_{\theta}\left(y_{t} \mid y_{t-1}, \ldots, y_{t-p}, x_{t-1}, \ldots, x_{t-p}\right) \neq Q_{\theta}\left(y_{t} \mid y_{t-1}, \ldots, y_{t-p}\right)
$$

where $Q_{\theta}\left(y_{t} \mid \cdot\right)$ is the $\theta$-th conditional quantile of $y_{t}$ given ', which depends on $t$ and $0<\theta<$ 0 . Define $Y_{t-1} \equiv\left(y_{t-1}, \ldots, y_{t-p}\right), \quad X_{t-1} \equiv\left(x_{t-1}, \ldots, x_{t-p}\right), \quad Z_{t}=\left(X_{t}, Y_{t}\right) \quad$, and $F_{y_{t} \mid Z_{t-1}}\left(y_{t} \mid Z_{t-1}\right)$ and $F_{y_{t} \mid Y_{t-1}}\left(y_{t} \mid Y_{t-1}\right)$ are the conditional distribution function of $y_{t}$ given $Z_{t-1}$ and $Y_{t-1}$, respectively.

The conditional distribution $F_{y_{t} \mid z_{t-1}}\left(y_{t} \mid Z_{t-1}\right)$ is assumed to be absolutely continuous in $y_{t}$ for almost all $Z_{t-1}$. If we denote $Q_{\theta}\left(Z_{t-1}\right) \equiv Q_{\theta}\left(y_{t} \mid Z_{t-1}\right)$ and $Q_{\theta}\left(Y_{t-1}\right) \equiv Q_{\theta}\left(y_{t} \mid Y_{t-1}\right)$, we have, $F_{y_{t} \mid Z_{t-1}}\left\{Q_{\theta}\left(Z_{t-1}\right) \mid Z_{t-1}\right\}=\theta$ w.p.1. Consequently, the hypothesis to be tested based on definitions (1) and (2) are

$$
\begin{array}{ll}
H_{0}=P\left[F_{y_{t} \mid Z_{t-1}}\left(Q_{\theta}\left(Y_{t-1}\right) \mid Z_{t-1}\right)=\theta\right]=1 & \text { a.s. } \\
H_{1}=P\left[F_{y_{t} \mid Z_{t-1}}\left(Q_{\theta}\left(Y_{t-1}\right) \mid Z_{t-1}\right)=\theta\right]<1 & \text { a.s. }
\end{array}
$$

Jeong et al., (2012) employs a distance the measure $J=\left[\varepsilon_{t} E\left(\varepsilon_{t} \mid Z_{t-1}\right) f_{Z}\left(Z_{t-1}\right)\right]$ where $\varepsilon_{t}$ is the regression error term and $f_{Z}\left(Z_{t-1}\right)$ is the marginal density function of $Z_{t-1}$. The regression error $\varepsilon_{t}$ arises from the fact that the null hypothesis in (3) can only be true if and only if $E\left(\mathbf{1}\left[y_{t} \leq Q_{\theta}\left(Y_{t-1}\right) \mid Z_{t-1}\right]\right)=\theta$ or equivalently $\mathbf{1}\left[y_{t} \leq Q_{\theta}\left(Y_{t-1}\right)\right]=\theta+\varepsilon_{t}$, where $\mathbf{1}[\cdot]$ is the indicator function. Jeong et al., (2012) specify the distance function as

$$
J=\left[\varepsilon_{t} E\left(\varepsilon_{t} \mid Z_{t-1}\right) f_{Z}\left(Z_{t-1}\right)\right]
$$


In equation (5), it is important to note that $J \geq 0$ and the equality holds if and only if the null hypothesis $H_{0}$ in equation (3) is true, while $J>0$ holds under the alternative $H_{1}$ in equation (4). Jeong et al., (2012) shows that the feasible kernel-based test statistic based on $J$ has the following form:

$$
\hat{J}_{T}=\frac{1}{T(1-1) h^{2 p}} \sum_{t=p+1}^{T} \sum_{s=p+1, s \neq t}^{T} K\left(\frac{Z_{t-1}-Z_{s-1}}{h}\right) \hat{\varepsilon}_{t} \hat{\varepsilon}_{s}
$$

where $K(\cdot)$ is the kernel function with bandwidth $h$ and $\hat{\varepsilon}_{t}$ is the estimate of the unknown regression error, which is estimated from

$$
\hat{\varepsilon}_{t}=\mathbf{1}\left[y_{t} \leq \hat{Q}_{\theta}\left(Y_{t-1}\right)\right]-\theta
$$

where $\hat{Q}_{\theta}\left(Y_{t-1}\right)$ is an estimate of the $\theta$-th conditional quantile of $y_{t}$ given $Y_{t-1}$. We estimate $\hat{Q}_{\theta}\left(Y_{t-1}\right)$ using the nonparametric kernel method as

$$
\hat{Q}_{\theta}\left(Y_{t-1}\right)=\hat{F}_{y_{t} \mid Y_{t-1}}^{-1}\left(\theta \mid Y_{t-1}\right)
$$

Here, $\hat{F}_{y_{t} \mid Y_{t-1}}\left(y_{t} \mid Y_{t-1}\right)$ is the Nadarya-Watson kernel estimator is given by

$$
\hat{F}_{y_{t} \mid Y_{t-1}}\left(y_{t} \mid Y_{t-1}\right)=\frac{\sum_{s=p+1, s \neq t}^{T} L\left(\frac{Y_{t-1}-Y_{s-1}}{h}\right) \mathbf{1}\left(y_{s} \leq y_{t}\right)}{\sum_{s=p+1, s \neq t}^{T} L\left(\frac{Y_{t-1}-Y_{s-1}}{h}\right)}
$$

with the kernel function $L(\cdot)$ and bandwidth $h$.

As an extension of Jeong et al.,'s (2012) framework, Balcilar et al., (2018) use a test for the second moment which allows us to test the causality between oil uncertainty and excess bond returns volatility. Causality in the $m$-th moment implies causality in the $k$-th moment for $m<$ $k$. To test for nonparametric Granger quantile causality in variance we employ the general nonparametric Granger quantile causality test by Nishiyama et al., (2011). Equation (10) is an illustration of the causality in higher order moments given as

$$
y_{t}=g\left(Y_{t-1}\right)+\sigma\left(X_{t-1}\right) \varepsilon_{t}
$$

where $\varepsilon_{t}$ is a white noise process, $g(\cdot)$ and $\sigma(\cdot)$ are unknown functions that satisfy certain conditions for stationarity. The specification in equation (10), does not allow Granger causality from $x_{t}$ to $y_{t}$, but certainly allows predictive power (in the Granger causality test) from $X_{t-1}$ to $y_{t}^{2} . \sigma(\cdot)$ is a general nonlinear function. A model like equation (10) has a null and alternative hypothesis for causality in variance given by

$$
\begin{aligned}
& H_{0}=P\left[F_{y_{t}^{2} \mid Z_{t-1}}\left(Q_{\theta}\left(Y_{t-1}\right) \mid Z_{t-1}\right)=\theta\right]=1 \\
& H_{1}=P\left[F_{y_{t}^{2} \mid Z_{t-1}}\left(Q_{\theta}\left(Y_{t-1}\right) \mid Z_{t-1}\right)=\theta\right]<1
\end{aligned}
$$

To obtain the feasible test statistic for testing the null hypothesis $H_{0}$ in equation (11) we replace $y_{t}$ in equations (6)-(9) with $y_{t}^{2}$. To overcome the problem that causality in the conditional first 
moment (mean) implies causality in the second moment (variance), we interpret quantile causality in higher order moments using the following model:

$$
y_{t}=g\left(X_{t-1}, Y_{t-1}\right)+\varepsilon_{t}
$$

Higher order quantile causality for this model can be specified as

$$
\begin{array}{ll}
H_{0}=P\left[F_{y_{t}^{k} \mid Z_{t-1}}\left(Q_{\theta}\left(Y_{t-1}\right) \mid Z_{t-1}\right)=\theta\right]=1 & \text { for } k=1,2, \ldots, K \\
H_{1}=P\left[F_{y_{t}^{k} \mid Z_{t-1}}\left(Q_{\theta}\left(Y_{t-1}\right) \mid Z_{t-1}\right)=\theta\right]<1 & \text { for } k=1,2, \ldots, K
\end{array}
$$

Following this definition, $x_{t}$ Granger causes $y_{t}$ in quantile $\theta$ up to $K$-th moment. The null specified in equation (11) is used to construct the test statistic in equation (6) for each $k$. It is difficult to combine the different statistics for each $k=1,2, \ldots, K$ into one statistic for the joint null in equation (14) because the statistics are mutually correlated (Nishiyama et al., 2011). To address this problem, we follow the sequential testing approach in Nishiyama et al., (2011). This approach first tests for nonparametric Granger causality in the first moment $(k=1)$. Rejecting the null hypothesis of non-causality means that we can stop and interpret this result as a strong indication of possible quantiles-based Granger causality in variance. However, failure to reject the null for $k=1$, does not automatically translate to no causality in the second moment and, thus, we can still construct the tests for $k=2$. This approach allows us to test the existence of causality only in variance as well as the causality in the mean and variance successively. It follows from Jeong et al., (2013) that $T h^{p} \hat{J}_{T} \rightarrow_{L} N\left(0, \sigma_{0}^{2}\right)$, where $\sigma_{0}^{2}=$ $2 E\left\{\sigma_{\varepsilon}^{4}\left(Z_{t-1}\right) f\left(Z_{t-1}\right)\right\}\left\{\int K^{2}(u) d u\right\}$ and $\sigma_{\varepsilon}^{4}\left(Z_{t-1}\right)=E\left[\varepsilon_{t}^{2} \mid Z_{t-1}\right]=\theta(1-\theta)$. Thus, the rescaled statistics $T h^{p} \hat{J}_{T} / \hat{\sigma}_{0}$ is asymptotically distributed as standard normal, where $\hat{\sigma}_{0}=$ $\sqrt{2} \theta(1-\theta) \sqrt{1 /\left(T(T-1) h^{2 p}\right)} \sqrt{\sum_{t \neq s} K^{2}\left(\left(W_{t-1}-W_{s-1}\right) / h\right)}$.

The empirical implementation of causality testing via quantiles entails specifying three key parameters: the bandwidth $(h)$, the lag order $(p)$, and the kernel types for $K(\cdot)$ and $L(\cdot)$. Our lag order is based on the Schwarz Information Criterion (SIC), with $h$ determined by the leaveone-out least-squares cross validation (as suggested by Racine and $\mathrm{Li}$ (2004), and Li and Racine (2004)), and for $K(\cdot)$ and $L(\cdot)$, we use Gaussian kernels for both first and second-moments of the bond risk premium.

\section{Data and Results}

Our analysis involves two variables namely, the excess bond returns and oil price uncertainty over the monthly period of 1953:06 to 2016:12, with the start- and end-dates being purely driven by data availability of the bond prices. $r x^{(n)}$ denote the continuously compounded excess returns on an $n$-year zero coupon bond, with $n=2,3,4$ and $5 .^{3}$ We obtain monthly US Treasury bond prices from the Fama and Bliss (1987) dataset, which is available at the Center for

\footnotetext{
${ }^{3}$ In line with Cochrane and Piazzesi (2005), we use the following notation for the (log) yield of an $n$-year bond: $y_{t}^{(n)} \equiv-\frac{1}{n} p_{t}^{(n)}$, where $p_{t}^{(n)}=\ln P_{t}^{(n)}$ is the $\log$-price of the $n$-year zero coupon bond at time $t$. A forward rate at time $t$ for loans between time $t+n-1$ and $t+n$ is defined as: $f_{t}^{(n)} \equiv p_{t}^{(n-1)}-p_{t}^{(n)}$. The $\log$ holding period return from buying an $n$-year bond at time $t$ and selling it as an $n-1$ year bond at time $t+1$ is: $r_{t+1}^{(n)}=p_{t+1}^{(n-1)}-$ $p_{t}^{(n)}$. The risk premium on an $n$-year discount bond over a short-term bond is the difference between the holding period returns of the $n$-year bond and the 1 -period interest rate, $r x_{t+1}^{(n)} \equiv r_{t+1}^{(n)}-y_{t}^{(1)}$. Alternatively, $r x_{t}^{(n)} \equiv$ $r_{t}^{(n)}-y_{t-1}^{(1)}$
} 
Research in Security Prices (CRSP). This is undoubtedly the most widely-used database to compute US bond premia (Ludvigson and $\mathrm{Ng}$, 2009, 2011), which in turn, is primarily because of the length of its coverage spanning over more than half a century. Using this data set, also allows us to place our paper in the existing literature on bond premia predictability. Of course an alternative would have been to use the bond yield of various maturities as developed by Gürkaynak et al., (2007), and then compute the bond premia using the Dynamic Nelson-Siegel model of Diebold and Li (2006). But this would have resulted in the dependent variable, to be model-specific, which we wanted to avoid, given that our oil uncertainty variable as discussed below, being latent, is also model-contingent.

As far as oil price uncertainty (OILUNC1) is concerned, we use the fitted conditional variance derived from a Generalized Autoregressive Conditional Heteroskedasticity $(\operatorname{GARCH}(1,1))$ model along the lines of Elder and Serletis (2010, 2011), and following Sadorsky (2006), Bos et al., (2018) and Gupta and Yoon (2018). ${ }^{4}$ In this regard, we use the West Texas Intermediate (WTI) oil price data derived from the Global Financial Database.

The variables of interest, i.e., the bond risk premia with maturities of 2-, 3-, 4-, and 5-year, as well as the derived measure of oil price uncertainty have been plotted in Figure A1, with their basic statistics summarized in Table A1, both of which can be found in the Appendix of the paper. As can be seen from Table A1, the null hypothesis of normality is rejected for both variables $\left(r x^{(n)}\right.$ and OILUNC1) of concern, and hence, provides motivation to rely on a quantiles-based analysis instead of a standard linear test of causality, due to the existence of heavy-tails.

Before we discuss the findings from the causality-in-quantiles test, for the sake of completeness and comparability, we first provide the findings from the standard linear Granger causality test reported in Table A2 in the Appendix of the paper. As shown in Table A2, the null of nocausality from OILUNC1 to $r x^{(n)}$, with $n=2,3,4$ and 5, cannot be rejected even at the $10 \%$ level of significance. In other words, a standard linear test of predictability fail to provide any evidence of significant oil uncertainty-related effects on excess bond returns.

Given the insignificant results obtained from the linear causality tests, next we statistically examine the presence of nonlinearity and structural breaks in the relationship between excess bond returns and oil price uncertainty, motivated from the evidence provided by Gargano et al., (2017) on the instability in the relationship between bond premia and its predictors. For these purposes, we apply the Brock et al., (1996) (BDS) test of nonlinearity on the residuals recovered from excess bond returns equation of the Granger causality test, and the Bai and Perron (2003) tests of multiple structural breaks on the same excess returns equation. As can be seen from Table A3 in the Appendix of the paper, the null hypothesis of i.i.d. residuals at various embedded dimensions $(m)$ is rejected at the highest significance level by the BDS test. In other words, the relationship between excess bond returns at the four maturities considered and the oil price uncertainty is in fact nonlinear. Further, based on the structural break test, we were able to detect one break each at 1981:12, 1981:11, 1981:07, and 1981:07 in the relationship between OILUNC1 with $r x^{(2)}, r x^{(3)}, r x^{(4)}$, and $r x^{(5)}$ respectively. These break dates seem to be in line with the findings of Smith and Taylor (2009) regarding a shift in the termstructure, and is believed to be a result of Paul Volcker's strong disinflationary policies to curb double digit inflation rates in the US (to some extent due to the second major oil-price shock

\footnotetext{
${ }^{4}$ Complete details of the estimation of the $\operatorname{GARCH}(1,1)$ model is available upon request from the authors.
} 
in 1979). In sum, in the presence of nonlinearity and regime changes, the findings based on the linear Granger causality test cannot be deemed robust and reliable. ${ }^{5}$ Hence, we now turn our attention to the causality-in-quantiles test, which is robust to linear misspecification given its nonparametric (i.e., data-driven) estimation, besides its ability to study the entire conditional distribution of not only returns, but also volatility (squared returns) of the US bond market.

In Figure 1, we present the results for the $k$-th order causality-in-quantiles test for excess bond returns and squared returns, i.e., volatility, emanating from OILUNC1 over the quantile range of 0.05 to 0.95 . Note the test statistic, proposed by Balcilar et al., (2018), follows a standard normal distribution, and we evaluate the existence or non-existence of causality at a specific quantile $(\tau)$, if the test statistic is greater than or less than the conventional $5 \%$ critical value of 1.96. We find that for $r x^{(1)}$ and its squared-value, the predictability holds over the entire conditional distribution, with stronger effects around the tails. A similar picture emerges for $r x^{(5)}$ though, there is no evidence of predictability around the quantile range of 0.4250 to 0.500 for the bond returns. ${ }^{6}$

Interestingly, the impact of OILUNC1 on $r x^{(3)}$ and $r x^{(4)}$ are also quite similar. For excess bond returns of maturities of 3 and 4-year, causality hold over the moderately high quantile range of 0.700 to 0.850 , and at $\tau=0.250$ for the latter. In terms of squared returns, i.e., volatility of these two maturities, the coverage of causality over the conditional distributions is much broader and ranges between 0.100 to 0.800 , and 0.100 to 0.700 for the 3 - and 4-year squared bond premia respectively.

\section{[INSERT FIGURE 1]}

Although we can derive robust predictive inference based on the causality-in-quantiles test, it would also be interesting to estimate the direction of the effects of oil uncertainty on bond market movements at various quantiles. However, in a nonparametric framework, this is not straightforward, with us requiring to employ the first-order partial derivatives. Estimation of the partial derivatives for nonparametric models can experience complications because nonparametric methods exhibit slow convergence rates, which can depend on the dimensionality and smoothness of the underlying conditional expectation function. But one could look at a statistic that summarizes the overall effect or the global curvature (i.e., the global sign and magnitude), but not the entire derivative curve. In this regard, a natural measure of the global curvature is the average derivative (AD). We use the locally polynomial quantile kernel regression approach of Chaudhuri et al., (1997), to estimate the partial ADs. The confidence intervals for AD estimates are obtained using the bootstrap method of Cai et al.,

\footnotetext{
${ }^{5}$ When we conducted the tests of slope equality and conditional symmetry, as developed by Koenker and Bassett (1982) and Newey and Powell (1987) respectively, on the equations used to test the linear Granger causality test, the corresponding null hypotheses were overwhelmingly rejected, suggesting the preference of a quantiles-based model over a conditional mean framework. Since these tests are applicable only on a linear model and not available for in a nonparametric context, we have discussed the tests in this footnote and have not presented them formally in the paper, but complete details are available upon request from the authors.

${ }^{6}$ As pointed out by an anonymous referee, an interesting observation is the volatility of the statistic at the lower conditional quantiles of the squared values of $r x^{(5)}$, though the causality still holds. It must be realized that, we use a nonparametric causality-in-quantiles test, which is purely data-driven, and hence the variability of the strength of the causal relationship is possibly an indication of the fluctuation in the available number of observations across the quantiles of the conditional distribution of the variance of $r x^{(5)}$. This line of reasoning is further corroborated by the fact that $r x^{(5)}$ has the highest positive skewness among all the bond premia considered (as reported in Table A1), and hence, has more data on the right tail rather than the left tail.
} 
(2000). The sign of the impact of oil price uncertainty on excess bond returns and volatility is reported in Figure 2. As can be observed, the effect of OILUNC1 on the returns and variance of bond premia of the four maturities considered is generally positive and significant at the 5\% level, corresponding to the quantiles for which predictability was detected based on the causality-in-quantiles test.

\section{[INSERT FIGURE 2]}

In sum, we can draw the following observations: (a) Impact of oil price uncertainty is stronger on bond volatility than returns across the four maturities considered, which is somewhat expected in the sense that uncertainty being itself capturing volatility (risk) in the oil market, is likely to have stronger higher-order impact on the bond market (see, Bonaccolto et al., (2018) for a detailed discussion in this regard); (b) Further, the effect of oil uncertainty on both returns and volatilities of the bonds with shortest and longest maturities is stronger relative to the corresponding metrics of the bonds with medium-term maturities. Intuitively, this result seems to be in line with the widespread observation that the two-ends of the term-structure tends to be affected by shocks relatively more compared to its other parts. For instance, the strongmovement in the 2-year bond premium due to oil uncertainty is probably due to the (expansionary) response of monetary policy to oil market uncertainty (to curb the recessionary impact), given the findings of Bauer (2015) and Tillmann (forthcoming), that bonds with shorter maturities are tied more strongly with monetary policy decisions. At the same time, the stronger impact of oil uncertainty on the 5-year bond premium is due to the possibility of the longer maturities being tied more closely to economic activity and inflationary expectations (Ang et al., 2011) - both of which (output and inflation) are affected by oil volatility (Castillo et al., 2007; Lu et al., 2010), and; (c) Finally, oil market uncertainty is priced in the excess bond returns, and also increases variability of the associated risk, with the result being in line with observations made for equity markets in the wake of increased overall macroeconomic uncertainty (Pástor and Veronesi, 2013). Note that, risks due to recession and inflationary expectations results in higher bond premium for the longest maturity, as investors need to be compensated for holding these bonds. As far as the shortest maturity is concerned, expansionary monetary policy shocks would enhance consumption growth and lead to lower returns on risk-free assets. Thus, when consumption growth is expected to be high, a decrease in the bond's payoff should make investors less willing to invest in shorter-term bonds and lead to a higher risk premium (Rudebusch and Swanson, 2012).

In the Appendix B of the paper, we conduct robustness and additional analyses based on the causality-in-quantiles framework. ${ }^{7}$ The main results, discussed above, are found to be robust under alternative measures of oil market uncertainty and implied measures of bond volatility. In addition, oil uncertainty is also shown to impact the equity premium and excess returns on corporate bonds, as well as their respective volatilities.

\footnotetext{
${ }^{7}$ As with the bond premia, linear causality tests failed to detect any evidence of causality in the first moment of all the dependent variables considered below corresponding to various measures of oil price uncertainty, and the BDS test showed significant evidence of nonlinearity. Hence, we decided to rely on the causality-in-quantiles test. In addition, oil uncertainty was consistently observed to have positive impact on the first- and second-moments of the alternative variables of interest, as in the case of the bond premia. Complete details of these test results are available upon request from the authors.
} 


\section{Concluding Remarks}

In this paper, we test the predictability of the movements of excess returns on US Treasury bonds due to oil price uncertainty over the monthly period of 1953:06 to 2016:12. We first indicate that, the relationship between bond premia of maturities of 2-, 3-, 4- and 5-year with oil uncertainty is nonlinear and has undergone regime-changes, and hence, the evidence of nocausality derived from the misspecified linear model cannot be relied upon. Given this, we use a $k$-th order nonparametric causality-in-quantiles framework, which in turn, allows us to test for predictability over the entire conditional distribution of not only bond returns, but also volatility, by controlling for misspecification due to uncaptured nonlinearity and structural breaks. Our results point out that oil uncertainty not only predicts US bond returns, but also volatility, with the effect on the latter being stronger. In addition, the impact is positive, i.e., oil uncertainty increases the bond premia and its volatility across maturities. In line with the theory of term-structure, our results also show that oil uncertainty tends to have a stronger impact on the shortest and longest maturities considered, and relatively weaker impact on bonds with medium-term maturities. These main results are found to be robust under alternative measures of oil market uncertainty and implied measures of bond volatility. Finally, oil uncertainty is also shown to impact the equity premium and excess returns on corporate bonds, as well as their respective volatilities.

Our results have important implications for not only bond investors and policymakers, but also for academics in finance, who are all looking to predict interest rates movements accurately. The finding that oil uncertainty impact the evolution of future interest rates and its volatility can help policymakers in better design monetary policy, by accounting for oil price volatility. Bond investors can improve investment strategies by exploiting the role of the oil price uncertainty for interest-rate predictability. Finally, researchers may find our results useful for developing better asset-pricing models that appropriately use the information embedded in estimates of oil market uncertainty.

As part of future research, it would be interesting to extend our analysis to a full-fledged forecasting exercise involving the bond market as in Ludvigson and $\mathrm{Ng}(2009,2011)$, since insample predictability does not guarantee the same over an out-of-sample period.

\section{References}

Andersen, T., and Bollerslev, T. (1998). Answering the skeptics: Yes, standard volatility models do provide accurate forecasts. International Economic Review, 39, 885-905

Ang, A., Boivin, J., Dong, S., and Loo-Kung, R. (2011). Monetary Policy Shifts and the Term Structure. Review of Economic Studies, 78(2), 429-457.

Apergis, N. (2019). Oil prices and corporate high-yield spreads: Evidence from panels of nonenergy and energy European firms. The Quarterly Review of Economics and Finance, 72(C), 34-40.

Bahloul, W., Balcilar, M., Cunado, J., and Gupta, R. (2018). The role of economic and financial uncertainties in predicting commodity futures returns and volatility: Evidence from a nonparametric causality-in-quantiles test. Journal of Multinational Financial Management, 45(C), 52-71. 
Bai, J. and Perron, P. (2003). Computation and analysis of multiple structural change models. Journal of Applied Econometrics, 18, 1-22.

Balcilar, M., Gupta, R., Kyei, C., and Wohar, M.E. (2016). Does Economic Policy Uncertainty Predict Exchange Rate Returns and Volatility? Evidence from a Nonparametric Causality-inQuantiles Test. Open Economies Review, 27(2), 229-250.

Balcilar, M., Gupta R., Nguyen D.K., and Wohar, M.E. (2018). Causal effects of the United States and Japan on Pacific-Rim stock markets: nonparametric quantile causality approach. Applied Economics. DOI: https://doi.org/10.1080/00036846.2018.1488062.

Bams, D., Blanchard, G., Honarvar, I., and Lehnert, T. (2017). Does oil and gold price uncertainty matter for the stock market? Journal of Empirical Finance, 44(C), 270-285.

Bauer, M.D. (2015). Nominal Interest Rates and the News. Journal of Money, Credit and Banking, 47(2-3),

Bernanke, B.S. (1983). Irreversibility, uncertainty, and cyclical investment. Quarterly Journal of Economics, 98, 85-106.

Bonaccolto, G., Caporin, M., and Gupta, R. (2018). The dynamic impact of uncertainty in causing and forecasting the distribution of oil returns and risk. Physica A: Statistical Mechanics and its Applications, 507(C), 446-469.

Bos, M., Demirer, R., Gupta, R., and Tiwari, A.K. (2018). Oil returns and volatility: The role of mergers and acquisitions. Energy Economics, 71(C), 62-69.

Bouri, E., de Boyrie, M. E. and Pavlova, I. (2017). Volatility transmission from commodity markets to sovereign CDS spreads in emerging and frontier countries. International Review of Financial Analysis, 49(C), 155-165.

Bouri, E., Jalkh, N., and Roubaud, D. (2019). Commodity volatility shocks and BRIC sovereign risk: A GARCH-quantile approach. Resources Policy, 61, 385-392.

Bouri, E., Shahzad, S.J.H., Raza, N., and Roubaud, D. (2018). Oil volatility and sovereign risk of BRICS. Energy Economics, 70(C), 258-269.

Brock, W., Dechert, D., Scheinkman, J. and LeBaron, B. (1996). A test for independence based on the correlation dimension. Econometric Reviews, 15, 197-235.

Buraschi, A., Trojani, F., and Vedolin, A. (2013). Economic uncertainty, disagreement, and credit markets. Management Science, 60(5), 1083-1350.

Cai, Z., Fan, J., and Yao, Q. (2000). Functional-coefficient regression models for nonlinear time series. Journal of the American Statistical Association, 95(451), 941-956.

Campbell, J.Y., and Shiller, R.J. (1991). Yield Spreads and Interest Rates: A Birds Eye View. Review of Economic Studies, 58, 495-514.

Castillo, P., Montoro, C., and Tuesta, V. (2007). Inflation Premium and Oil Price Volatility. Centre for Economic Performance (CEP), Discussion Papers dp0782. 
Çepni, O., Demirer, R., Gupta, R., and Pierdzioch, C. (2019a). Time-Varying Risk Aversion and the Predictability of Bond Premia. Finance Research Letters. DOI: https://doi.org/10.1016/j.frl.2019.07.014.

Çepni, O., Guney, I.E., Gupta, R., Wohar, M.E. (Forthcoming). The Role of an Aligned Investor Sentiment Index in Predicting Bond Risk Premia of the United States. Journal of Financial Markets.

Çepni, O., Gupta, R., Wohar, M.E. (2019b). Variants of Consumption-Wealth Ratios and Predictability of U.S. Government Bond Risk Premia. International Review of Finance. DOI: https://doi.org/10.1111/irfi.12283.

Chan, J.C. (2017). The stochastic volatility in mean model with time-varying parameters: An application to inflation modeling. Journal of Business \& Economic Statistics, 35(1), 17-28.

Chaudhuri, P., Doksum, K., and Samarov, A. (1997). On average derivative quantile regression. The Annals of Statistics, 25(2), 715-744.

Choi, K., and Hammoudeh, S. (2010). Volatility behavior of oil, industrial commodity and stock markets in a regime-switching environment. Energy Policy, 38, 4388-4399.

Choi, H., Mueller, P., and Vedolin, A. (2017). Bond Variance Risk Premiums. Review of Finance, 2017, 21(3), 987-1022.

Chuliá, H., Gupta, R., Uribe, J.M., and Wohar, M.E. (2017). Impact of US uncertainties on emerging and mature markets: Evidence from a quantile-vector autoregressive approach. Journal of International Financial Markets, Institutions and Money, 48(C), 178-191.

Cochrane, J. H., and Piazzesi, M. (2005). Bond risk premia. American Economic Review, 95(1), 138-160.

Degiannakis, S., Filis, G., and Arora, V. (2018). Oil Prices and Stock Markets: A Review of the Theory and Empirical Evidence. The Energy Journal, 39(5), Article No. 4.

Diebold, F., and Li, C. (2006). Forecasting the term structure of government bond yields. Journal of Econometrics, 130(2), 337-364.

Elder, J., and Serletis, A. (2010). Oil Price Uncertainty. Journal of Money, Credit and Banking, 42(6), 1137-1159.

Elder, J., and Serletis, A. (2011). Volatility In Oil Prices And Manufacturing Activity: An Investigation of Real Options. Macroeconomic Dynamics, 15(S3), 379-395.

Elyasiani, E., Mansur, I., and Odusami, B. (2011). Oil price shocks and industry stock returns. Energy Economics, 33, 966-974.

Fama, E. F., and Bliss. R. H. (1987). The Information in Long-Maturity Forward Rates. American Economic Review, 77, 680-692.

Fama, E. F., and K. R. French. K. R. (1989). Business Conditions and Expected Returns on Stocks and Bonds. Journal of Financial Economics, 25, 23-49.

Gargano, A., Pettenuzzo, D., and Timmermann, A. (2019). Bond Return Predictability: Economic Value and Links to the Macroeconomy. Management Science, 65(2), v-vi, 459-954. 
Ghysels, E., Horan, C., and Moench, E. (2018). Forecasting through the Rear-view Mirror: Data Revisions and Bond Return Predictability. Review of Financial Studies, 31(2), 678-714.

Gilchrist, S., and Zakrajšek, E. (2012). Credit Spreads and Business Cycle Fluctuations. American Economic Review, 102(4), 1692-1720.

Gormus, N.A., Nazlioglu, S., and Soytas, U. (2018). High-yield bond and energy markets. Energy Economics, 69, 101-110.

Guidolin, M., Hyde, S., McMillan D., and Ono, S. (2009). Non-linear predictability in stock and bond returns: When and where is it exploitable? International Journal of Forecasting, 25(2), 373-399.

Gupta, R., Yoon, S-M. (2018). OPEC news and predictability of oil futures returns and volatility: Evidence from a nonparametric causality-in-quantiles approach. The North American Journal of Economics and Finance, 45(C), 206-214.

Gürkaynak, R., Sack, B., and Wright, J.H. (2007). The U.S. Treasury yield curve: 1961 to the present. Journal of Monetary Economics, 54(8), 2291-2304.

Habib, M. M., and Stracca L. (2015). Is There a Global Safe Haven? International Finance, 18(3), 281-298.

Hager, S. B. (2017). A global bond: Explaining the safe-haven status of US Treasury securities. European Journal of International Relations, 23(3), 557-580.

Jeong, K., Härdle, W.K., and Song, S. (2012). A consistent nonparametric test for causality in quantile. Econometric Theory, 28(4), 861-887.

Kang, W., Ratti, R. A., and Yoon, K. H. (2014). The impact of oil price shocks on US bond market returns. Energy Economics, 44, 248-258.

Kang, W., Ratti, R. A., and Yoon, K. H. (2015a). Time-varying effect of oil market shocks on the stock market. Journal of Banking \& Finance, 61, S150-S163.

Kang, W., Ratti, R. A., and Yoon, K. H. (2015b). The impact of oil price shocks on the stock market return and volatility relationship. Journal of International Financial Markets Institutions and Money, 34, 41-54.

Keim, D. B., and Stambaugh, R. F. (1986). Predicting Returns in the Stock and Bond Markets. Journal of Financial Economics, 17, 357-390.

Koenker, R., and Basset, G. (1982). Robust Tests for Heteroscedasticity Based on Regression Quantiles. Econometrica, 50(1), 43-62.

Kopyl, K.A., and Lee, J.B-T. (2016). How safe are the safe haven assets? Financial Markets and Portfolio Management, 30 (4), 453-482.

Laborda, R. and Olmo, J. (2014). Investor sentiment and bond risk premia. Journal of Financial Markets, 18, 206-233.

Li, Q., and Racine, J. (2004). Cross-validated local linear nonparametric regression. Statistica Sinica, 14(2), 485-512. 
Lu, W-C., Liu, T-K., Tseng, C-Y. (2010). Volatility transmissions between shocks to the oil price and inflation: evidence from a bivariate GARCH approach. Journal of Information and Optimization Sciences, 31(4), 927-939.

Ludvigson, S. C., and $\mathrm{Ng}$, S. (2009). Macro factors in bond risk premia. The Review of Financial Studies, 22(12), 5027-5067.

Ludvisgon, S. C., and Ng, S. (2011). A Factor Analysis of Bond Risk Premia. In A. Ulah, and D. Giles (eds.), Handbook of Empirical Economics and Finance, 313-372. London: Chapman and Hall.

Newey, W., and Powell, J.L. (1987). Asymmetric Least Squares Estimation and Testing. Econometrica, 55(4), 819-847.

Nishiyama, Y., Hitomi, K., Kawasaki, Y., and Jeong, K. (2011). A consistent nonparametric test for nonlinear causality - Specification in time series regression. Journal of Econometrics, $165,112-127$.

Pástor, L., and Veronesi, P. (2012). Uncertainty about government policy and stock prices. Journal of Finance, 67, 1219-1264.

Pástor, L., and Veronesi, P. (2013). Political uncertainty and risk premia. Journal of Financial Economics, 110, 520-545.

Racine, J., and Li, Q. (2004). Nonparametric estimation of regression functions with both categorical and continuous data. Journal of Econometrics, 119(1), 99-130.

Rudebusch, G.D. and Swanson, E.T. (2012). The bond premium in a DSGE model with longrun real and nominal risk", American Economic Journal: Macroeconomics, 4, 105-143.

Sadorsky, P. (2006). Modeling and forecasting petroleum futures volatility. Energy Economics, 28(4), 467-488.

Shahzad, S.J.H., Naifar, N., Hammoudeh, S., and Roubaud, D. (2017). Directional predictability from oil market uncertainty to sovereign credit spreads of oil-exporting countries: Evidence from rolling windows and cross-quantilogram analysis. Energy Economics, 68, 327339.

Salisu, A., and Oloko, T. F. (2015). Modelling oil price-US stock nexus: A VARMABEKKAGARCH approach. Energy Economics, 50, 1-12.

Smith, J.M., and Taylor, J.B. (2009). The Long and Short End of the Term Structure of Policy Rules. Journal of Monetary Economics, 56(7), 907-917.

Smyth, R., and Narayan, P.K. (218). What do we know about oil prices and stock returns? International Review of Financial Analysis, 57, 148-156.

Tillmann, P. (Forthcoming). Monetary Policy Uncertainty and the Response of the Yield Curve to Policy Shocks. Journal of Money, Credit and Banking.

Tiwari, A.K., Cunado, J., Gupta, R., and Wohar, M.E. (2018). Volatility Spillovers across Global Asset Classes: Evidence from Time and Frequency Domains. The Quarterly Review of Economics and Finance, 70, 194-202. 
van Eyden, R., Difeto, M., Gupta, R., and Wohar, M.E. (2019). Oil price volatility and economic growth: Evidence from advanced economies using more than a century's data. Applied Energy, 233-234, 612-621.

Wan, J. Y., and Kao, C. W. (2015). Interactions between oil and financial markets - Do conditions of financial stress matter? Energy Economics, 52, 160-175.

Zhu, X. (2015). Out-of-sample bond risk premium predictions: A global common factor. Journal of International Money and Finance, 51, 155-173. 

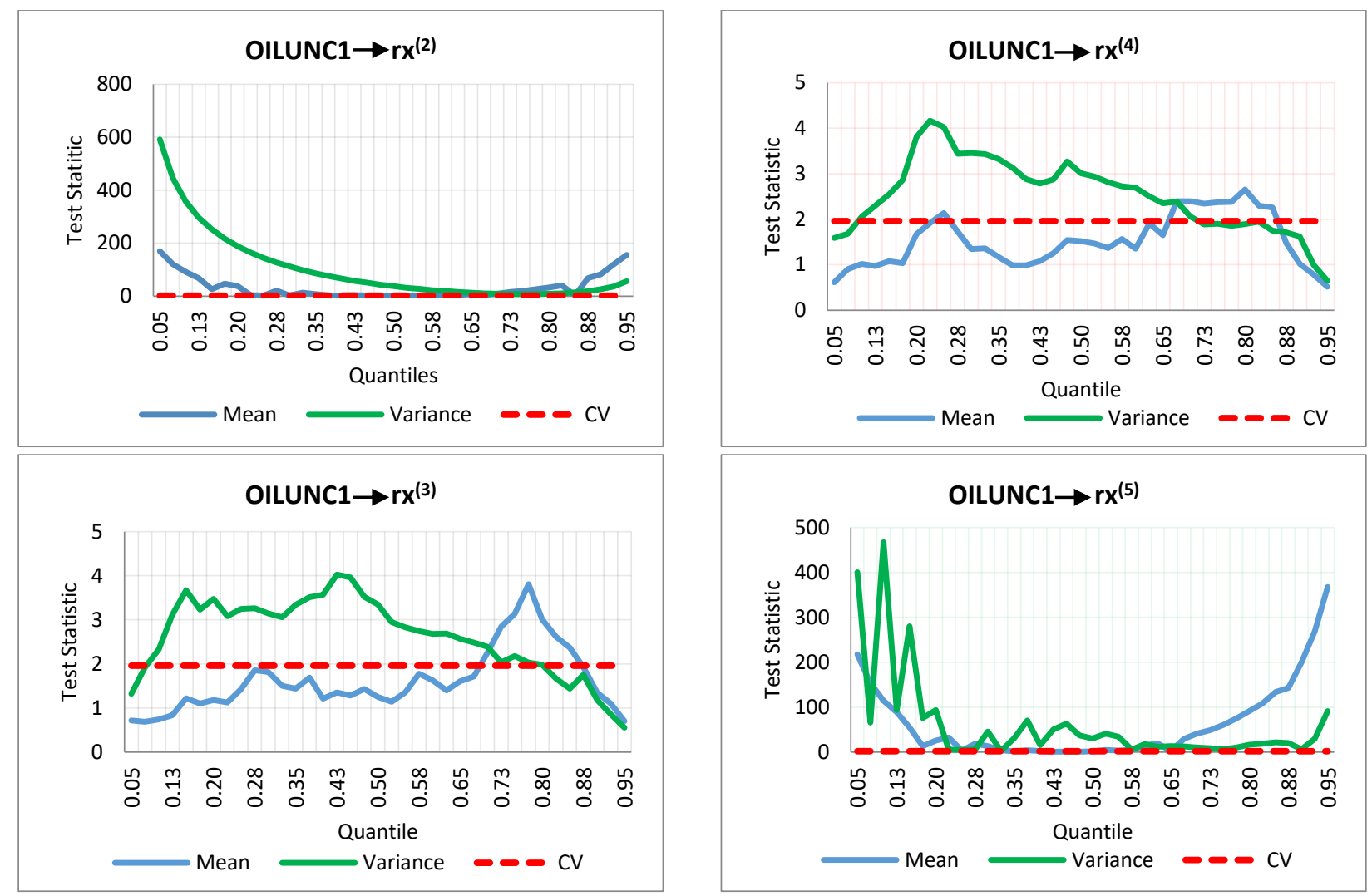

Figure 1. Causal Impact of GARCH $(1,1)$ Model-Based Oil Uncertainty (OILUNC1) on Bond Premium and Volatility

[Note: $\mathrm{rx}^{(2)}, \mathrm{rx}^{(3)}, \mathrm{rx}^{(4)}, \mathrm{rx}^{(5)}$ : excess bond premium of maturities of 2-, 3-, 4-, and 5-year relative to 1-year bond returns; $\mathrm{CV}$ is $5 \%$ critical value of 1.96 ]. 


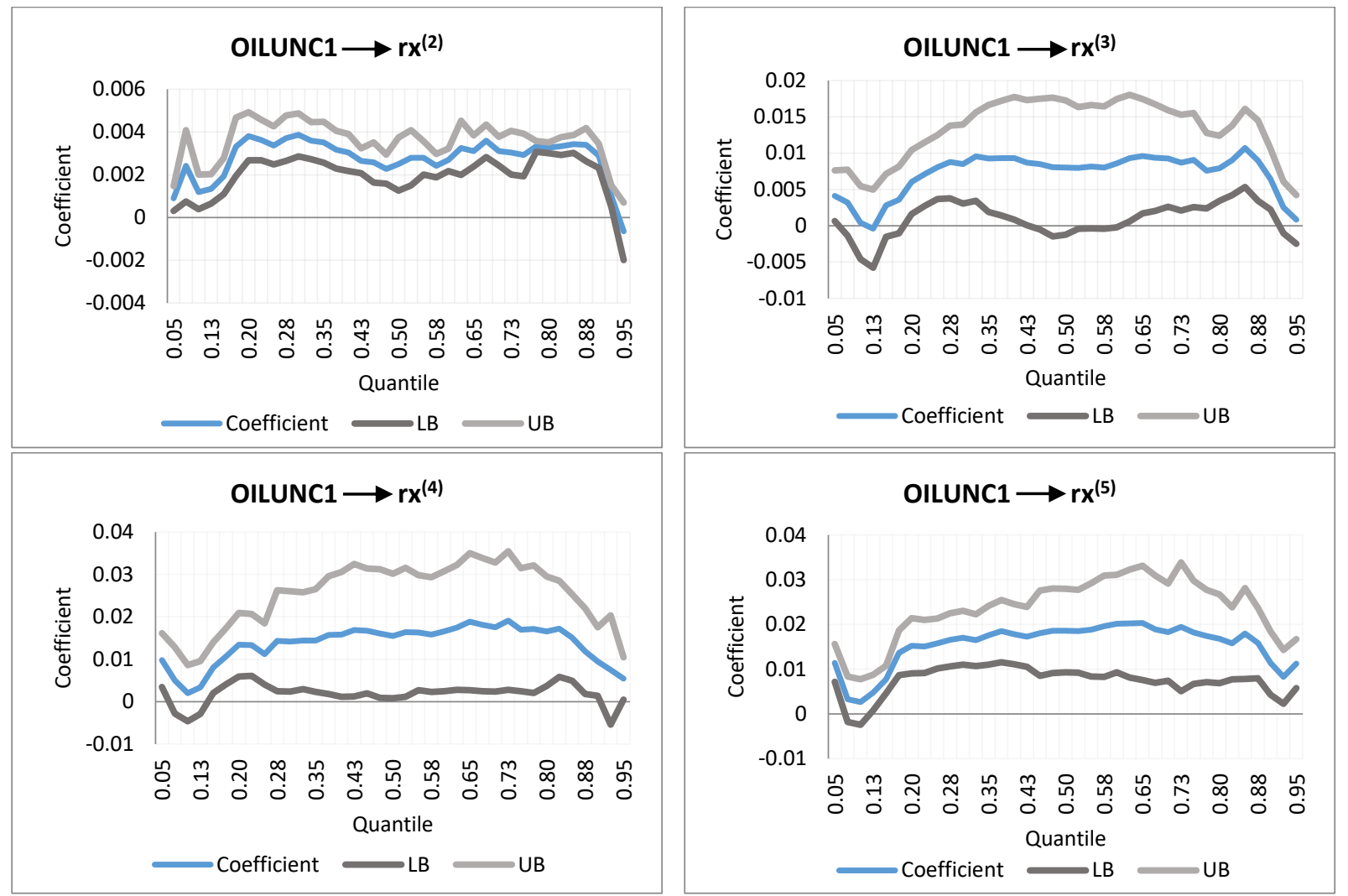

Figure 2(a). Sign of the Impact of Oil Uncertainty (OILUNC1) on Bond Premia [Note: See Notes to Figure 1; LB and UB stands for lower and upper 95\% confidence bands.]

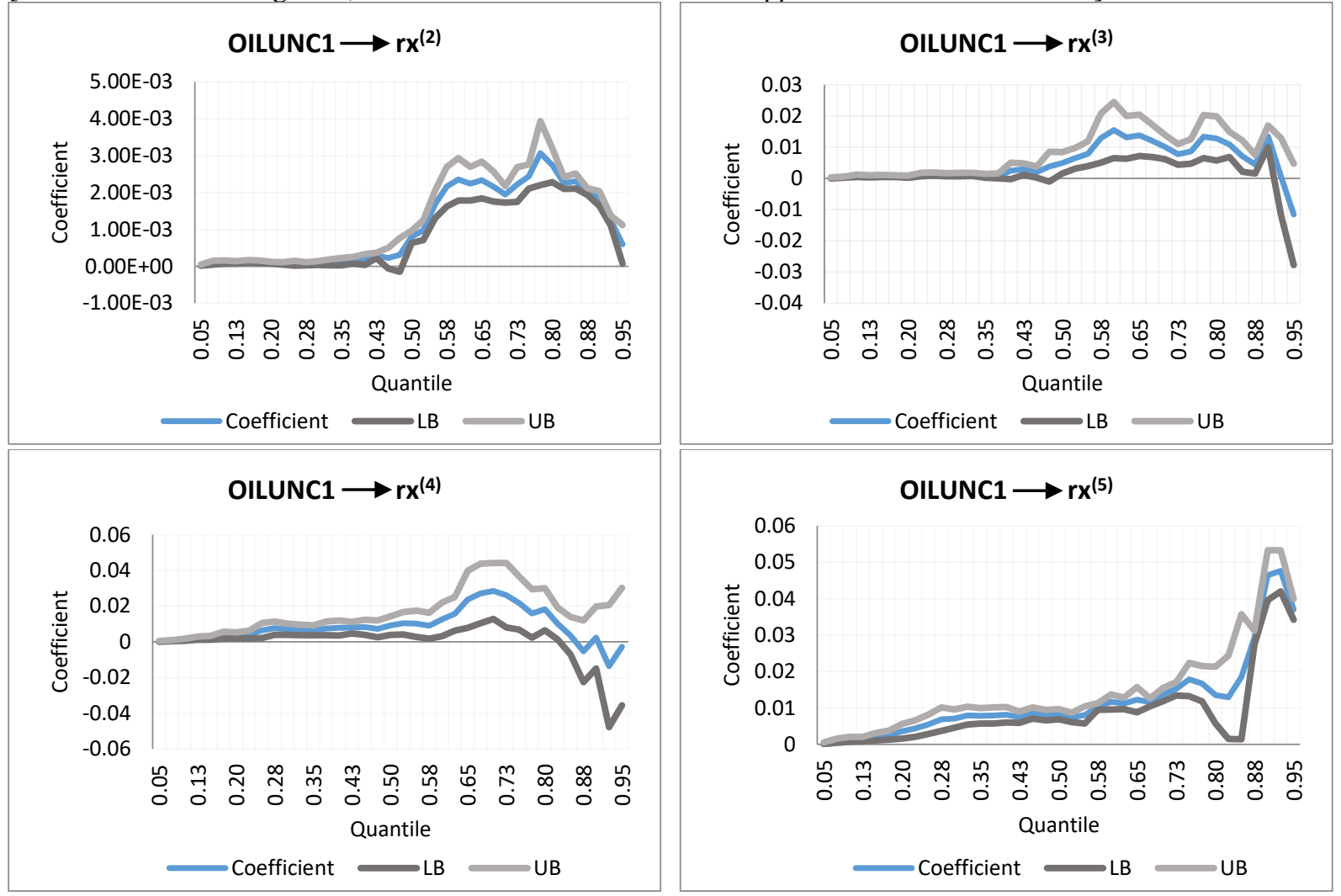

Figure 2(b). Sign of the Impact of Oil Uncertainty (OILUNC1) on Volatility of Bond Premium [Note: See Notes to Figure 1; See Notes to Figure 2(a)] 


\section{APPENDICES}

APPENDIX A:

Table A1. Summary Statistics

\begin{tabular}{|c|c|c|c|c|c|}
\hline & \multicolumn{5}{|c|}{ Variable } \\
\hline Statistic & $r x^{(2)}$ & $r x^{(3)}$ & $r x^{(4)}$ & $r x^{(5)}$ & OILUNC1 \\
\hline Mean & 0.00 & 0.01 & 0.01 & 0.01 & 0.01 \\
\hline S.D. & 0.02 & 0.03 & 0.04 & 0.05 & 0.01 \\
\hline Min & -0.06 & -0.10 & -0.14 & -0.18 & 0.00 \\
\hline Max & 0.06 & 0.10 & 0.14 & 0.17 & 0.10 \\
\hline Skewness & 0.13 & 0.03 & 0.06 & 0.05 & 3.80 \\
\hline Kurtosis & 0.92 & 1.02 & 0.92 & 0.83 & 17.87 \\
\hline JB & $29.46 * * *$ & $34.01 * * *$ & $28.26 * * *$ & $22.77 * * *$ & $12061.68 * * *$ \\
\hline $\mathrm{Q}(1)$ & $660.79 * * *$ & $665.25 * * *$ & $665.13 * * *$ & $652.67 * * *$ & $593.72 * * *$ \\
\hline $\mathrm{Q}(4)$ & $2084.67 * * *$ & $2076.65 * * *$ & $2080.87 * * *$ & $2028.00^{* * *}$ & $1547.27 * * *$ \\
\hline $\mathrm{ARCH}(1)$ & $500.37 * * *$ & $517.40 * * *$ & $509.58 * * *$ & $479.09 * * *$ & $393.58 * * *$ \\
\hline $\mathrm{ARCH}(4)$ & $503.00 * * *$ & $527.94 * * *$ & $518.78 * * *$ & $482.64 * * *$ & $409.02 * * *$ \\
\hline Observations & \multicolumn{5}{|c|}{ 1953:06-2016:12 (763) } \\
\hline
\end{tabular}

Note: $r x^{(i)}, \mathrm{i}=2,3,4$ and 5 represents the bond premium (relative to the 1-year bond) with maturities 2-, 3-, 4-, and 5-year; OILUNC1: is the GARCH(1,1) based estimate of oil price volatility, i.e., uncertainty; S.D.: Standard Deviation; JB: Jarque-Bera test of normality; *** indicates rejection of the null hypotheses of normality (JB), autocorrelation (Q-stat), and heteroskedasticity (ARCH) at $1 \%$ level of significance. 
Table A2. Linear Granger Causality Test Results

\begin{tabular}{|c|c|c|c|}
\hline Dependent Variable & $F$-statistic & $p$-value & $\operatorname{Lag}(\mathrm{s})$ \\
\hline$r x^{(2)}$ & 0.50 & 0.60 & 2 \\
\hline$r x^{(3)}$ & 0.52 & 0.60 & 2 \\
\hline$r x^{(4)}$ & 0.70 & 0.49 & 2 \\
\hline$r x^{(5)}$ & 0.94 & 0.33 & 1 \\
\hline
\end{tabular}

Note: See Notes to Table A1. The $F$-statistic has a null that OILUNC1 does not Granger causes $r x^{(i)}$, with $i=2,3$, 4 , 5, with optimal lag lengths chosen by the Schwarz Information Criterion (SIC).

Table A3. Brock et al. (1996, BDS) Test of Nonlinearity

\begin{tabular}{|c|r|r|r|r|c|}
\hline \multirow{2}{*}{$\begin{array}{c}\text { Dependent } \\
\text { Variable }\end{array}$} & \multicolumn{5}{|c|}{ Dimension $(m)$} \\
\cline { 2 - 6 } & \multicolumn{1}{|c|}{3} & \multicolumn{1}{c|}{4} & \multicolumn{1}{c|}{5} & 6 \\
\hline$r x^{(2)}$ & $8.42 * * *$ & $12.12 * * *$ & $17.86^{* * *}$ & $26.06 * * *$ & $40.40 * * *$ \\
\hline$r x^{(3)}$ & $5.20 * * *$ & $6.76 * * *$ & $9.21 * * *$ & $12.45 * * *$ & $18.10^{* * *}$ \\
\hline$r x^{(4)}$ & $5.50 * * *$ & $6.95 * * *$ & $8.82 * * *$ & $12.28 * * *$ & $18.42 * * *$ \\
\hline$r x^{(5)}$ & $6.44 * * *$ & $7.63 * * *$ & $9.84 * * *$ & $14.31 * * *$ & $23.31 * * *$ \\
\hline
\end{tabular}

Note: See Notes to Table A1. Entries correspond to the $z$-statistic of the BDS test which has the null of i.i.d. residuals, with the test applied to the residuals recovered from the excess bond returns $\left(r x^{(i)}\right)$ equation for $i=2,3$, 4, and 5, used in the Granger causality test due to OILUNC1 reported in Table A2; *** indicates rejection of the null hypothesis at $1 \%$ level of significance. 


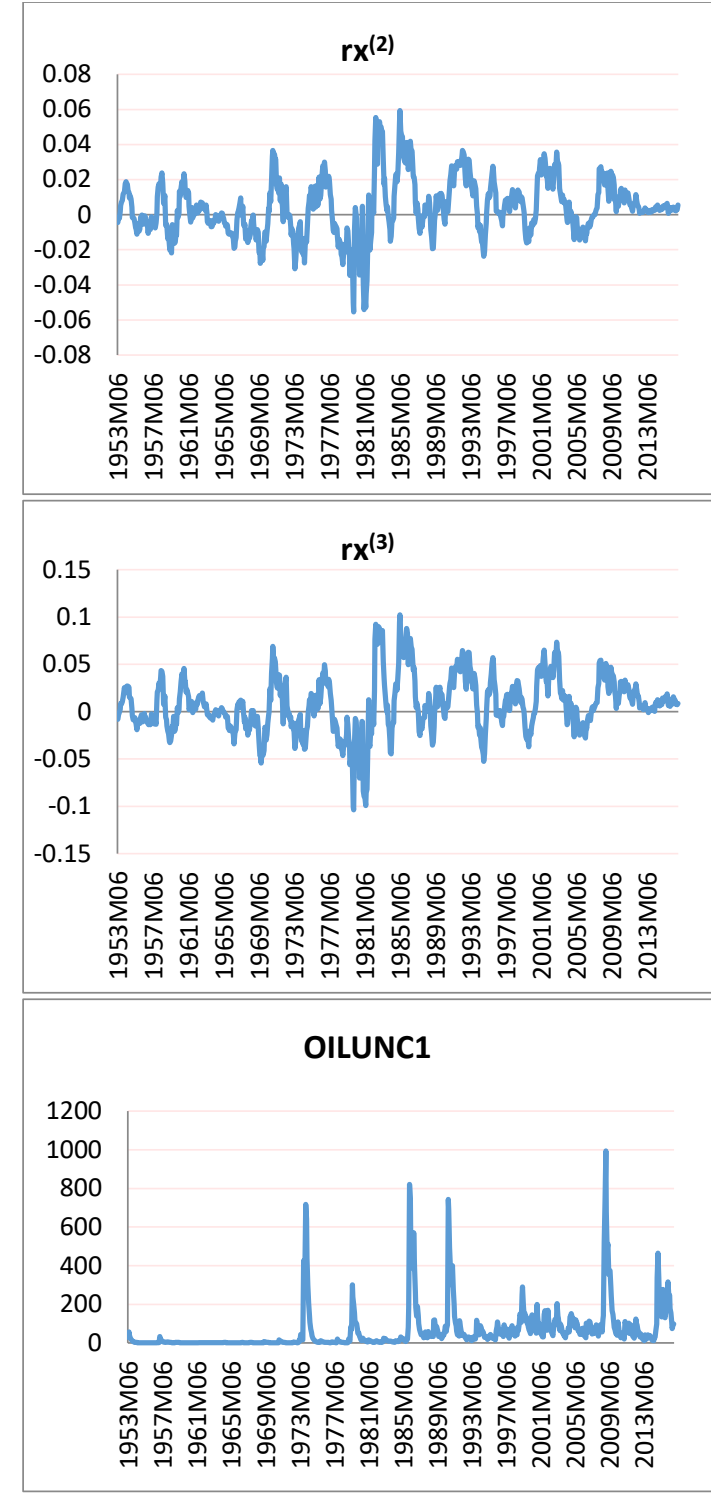

Figure A1. Data Plots

Note: See Notes to Table A1.

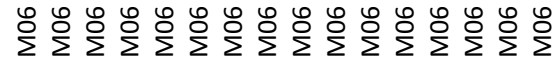

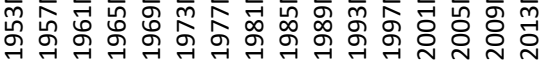

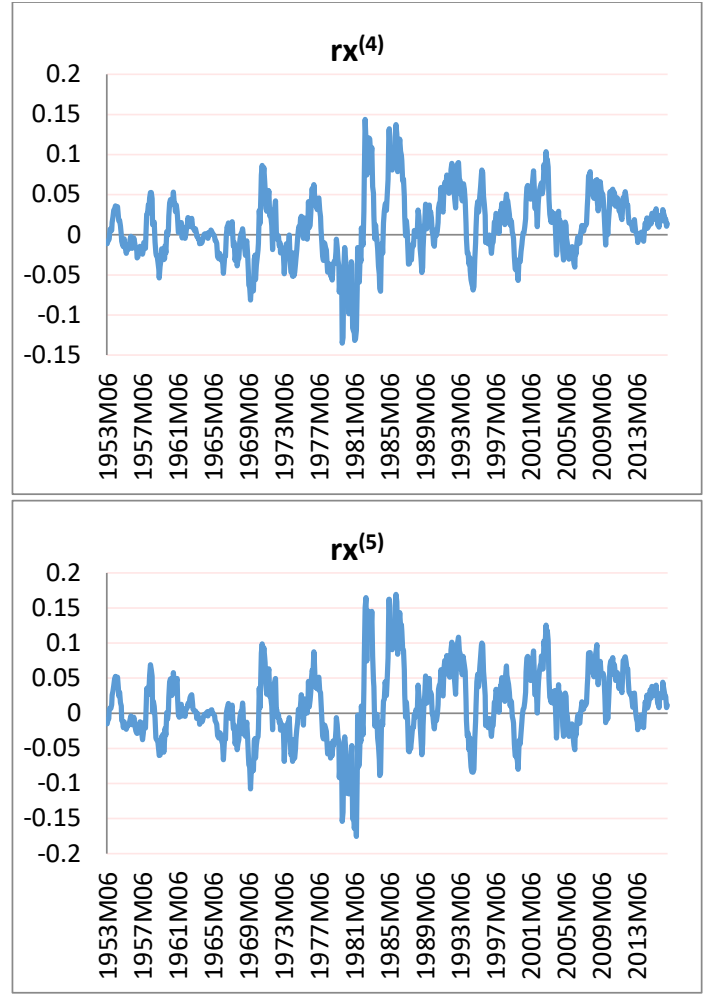




\section{APPENDIX B:}

\section{Robustness and Additional Analyses:}

We start-off by analysing the causal impact of two alternative measures of oil price uncertainty. Then, we also test for predictability of the movements of equity premium and corporate bond premium based on our benchmark measure of uncertainty. Finally, we also test for predictability of our GARCH(1,1)-based measure of oil price uncertainty on bond market variance derived from indices of implied volatility of the US Treasury market. Below, we discuss the results of each of these robustness checks in detail derived:

(i) We first derive two alternative measures of oil uncertainty, with OILUNC2 based on a time-varying parameter stochastic volatility (TVP-SV) model of Chan $(2017),{ }^{8}$ and OILUNC3 being a monthly measure of realized volatility, derived from sum of daily squared returns over a month as suggested in Andersen and Bollerslev (1998). In addition to these two measures of uncertainty, we also use the crude oil volatility index of the Chicago Board Options Exchange (CBOE), as the third alternative measure of oil market uncertainty (OILUNC4). ${ }^{9}$ Note that the analysis based on OILUNC2 ranges from 1953:06 to 2016:12, while given the availability of daily data (again sourced from the Global Financial Database), the causality-in-quantiles test with OILUNC3 covers 1977:08 to 2016:12. As far as OILUNC4 corresponding to the oil VIX is concerned, the sample period is 2007:05 to 2016:12. ${ }^{10}$ As can be seen from Figure B1, our benchmark results reported in Figure 1 with $O I L U N C 1$, in general, continues to hold under the two alternative measures of oil price uncertainty, i.e., OILUNC2 and OILUNC3. Specifically, we continue to see stronger impact (in terms of the coverage of the conditional distributions over which causality holds) on bond premium volatility relative to the excess returns, and also that the predictability of bond market movements (mean and variance) for shortest (2-year) and longest (5-year) maturities is relatively more powerful than the medium-term maturities (3- and 4-year). When it comes to OILUNC4, the impact on bond premia and volatility across the various maturities are quite similar, with no evidence of predictability at the extreme ends. In addition, the causality tends to get more powerful in strength as the maturity lengthens. In other words, compared to OILUNC1, OILUNC2, OILUNC3, there are some differences in the nature of predictability under the CBOE implied volatility index, i.e., OILUNC4, but more importantly, this measure too contains predictive power for the first- and secondmoments of the bond market. Note that, when we look at OILUNC1 and OILUNC2, the results are quite similar. There are however, differences in terms of the pattern of

\footnotetext{
${ }^{8}$ Complete details of the parameters derived from a Bayesian estimation of this model is available upon request from the authors.

${ }^{9}$ The CBOE Crude Oil ETF Volatility Index ("Oil VIX") measures the market's expectation of 30-day volatility of crude oil prices by applying the VIX methodology (see, http://www.cboe.com/vix for details) to United States Oil Fund, LP options spanning a wide range of strike prices. The daily data is available for download from: http://www.cboe.com/products/vix-index-volatility/volatility-on-etfs/cboe-crude-oil-etf-volatility-index-ovx.

${ }^{10}$ We take averages of the daily data over a month to convert the Oil VIX to the corresponding monthly frequency of OILUNC4. Using the last day of the month to measure the corresponding monthly value of OILUNC4, yielded qualitatively and quantitatively similar results to those reported in the paper, which in turn are available upon request from the authors.
} 
causality, when we analyze at OILUNC3 and OILUNC4 relative to the results derived under OILUNC1 and OILUNC2. Recall the sample periods for OILUNC3 and OILUNC4 are shorter compared to that under OILUNC1 and OILUNC2. So in some sense, with the nonparametric causality-in-quantiles approach requiring more data to provide reliable inferences, the results for OILUNC1 and OILUNC2, are likely to be more robust, especially given that the results obtained under these two measures of uncertainties are also consistent with theoretical intuition. But, the important message that must be derived from the usage of these alternative measures of oil market uncertainties is the consistent fact that the effect is stronger for volatility than on excess bond returns;

\section{[INSERT FIGURE B1]}

(ii) To validate the results of Bams et al., (2017) of predictability of the stock market movements due to oil uncertainty (OILUNC1), we applied the causality-in-quantiles test on the equity premium $(E P)$ and its squared value, i.e., volatility. The equity premium is obtained from the CRSP stock returns minus the risk free-rate, ${ }^{11}$ and cover the period of 1953:06 to 2016:12 to correspond to the same sample period of the bond market data. As can be seen from Figure B2, OILUNC1 fail to cause the extreme ends of the conditional distribution of excess returns, i.e., $\tau=0.050$ to 0.100 , and $\tau=0.825$ to 0.950 , and similar results are also obtained for stock market volatility, with no prediction over $\tau=0.050$ to 0.100 , and at $\tau=0.950$. Hence, as with the bond premia, oil uncertainty does affect both stock returns and volatility, with the effect being relatively stronger (in terms of coverage of the conditional distribution where the null of nocausality is rejected) for the latter;

\section{[INSERT FIGURE B2]}

(iii) As an additional analysis, we also conducted the causality-in-quantiles test from OILUNC1 on excess corporate bond premium (ECBP1), which is measured as longterm high yield corporate bond returns minus the risk free-rate, ${ }^{12}$ over the sample period of 1953:06 to 2016:12. As can be seen from Figure B3, predictability holds over the entire respective conditional distributions of the corporate bond premium and its volatility, with the impact being stronger on volatility than the first moment of corporate premium (especially from the quantile $(\tau)$ equal to 0.25 and above), just as in the case of the US Treasury bond premia; ${ }^{13}$

\footnotetext{
11 Data on both these variables are available for download from the website of Professor Amit Goyal at: http://www.hec.unil.ch/agoyal/.

${ }^{12}$ Data on the long-term corporate bond returns, derived from Ibbotson's Stocks, Bonds, Bills and Inflation Yearbook, is available for download from the website of Professor Amit Goyal at: http://www.hec.unil.ch/agoyal/, with.

${ }^{13}$ In addition, we also analyzed the predictability due to OILUNC1 of an alternative measure of excess corporate bond premium (ECBP2) as developed by Gilchrist and Zakrajšek (2012). The data on ECBP2 is available for download from: $\quad$ https://www.federalreserve.gov/econresdata/notes/feds-notes/2016/recession-risk-and-the-excess-bondpremium-20160408.html. Based on the sample period of 1973:01 to 2016:12, we observe from Figure B4 in the Appendix, that $E C B P 2$ is predictable from just below the median till moderately high quantiles (i.e., $\tau=0.475$ to 0.850 ). The volatility of $E C B P 2$, i.e., squared $E C B P 2$ is caused by $O I L U N C 1$ over the moderately low quantiles of $\tau=0.225$
} 


\section{[INSERT FIGURES B3 and B4]}

(iv) Finally in Figure B5, we also report the causality-in-quantiles test (for mean only) on the implied volatilities of US Treasuries with maturities of 5 (TIV5)-, 10 (TYVIX)- and 30 (TIV30)-years, which were developed by Choi et al., (2017). ${ }^{14}$ The sample periods, based on data availability are: 1990:01-2012:09, 1985:05-2015:12, and 1982:102012:09 for TIV5, TYVIX, and TIV30 respectively. Note that, the implied volatility measures are not available for bonds of any other maturity, and hence, our analysis was only restricted to TIV5, TYVIX, and TIV30. The decision to use these metrics were primarily to check, if an alternative measure of bond market volatility can be predicted by oil market uncertainty. OILUNC1 causes the entire conditional distribution of TIV30 and TYVIX (at the 10\% level of significance for quantile $(\tau=0.95)$, and also predicts TIV5, barring the ends of its conditional distribution, i.e., ( $\tau=0.050$ to 0.225 , and $\tau$ $=0.850$ to 0.950 ). These results tend to corroborate the earlier findings related to bond market volatility based on squared excess bond returns, i.e., of the strong impact of oil uncertainty on bond volatility especially at longer maturities.

[INSERT FIGURE B5]

to 0.350 . Unlike the case of US Treasury bonds and the long-term corporate bonds, the predictability due to oil uncertainty seems to be more stronger on the alternative measure of the excess corporate bond premium $(E C B P 2)$ than its volatility. Notwithstanding the differences in the sample period, the muted impact on ECBP2 compared to ECBP1 from OILUNC1, could be due to the fact that the former is a component of corporate bond credit spreads that is not directly attributable to expected default risk (Gilchrist and Zakrajšek, 2012). But in general again, the role of oil market uncertainty in predicting movements of the corporate bond premium cannot be ignored.

${ }^{14}$ The data on the implied volatility of US Treasuries can be downloaded from the website of Professor Andrea Vedolin at: https://sites.google.com/site/andreavedolin/. 

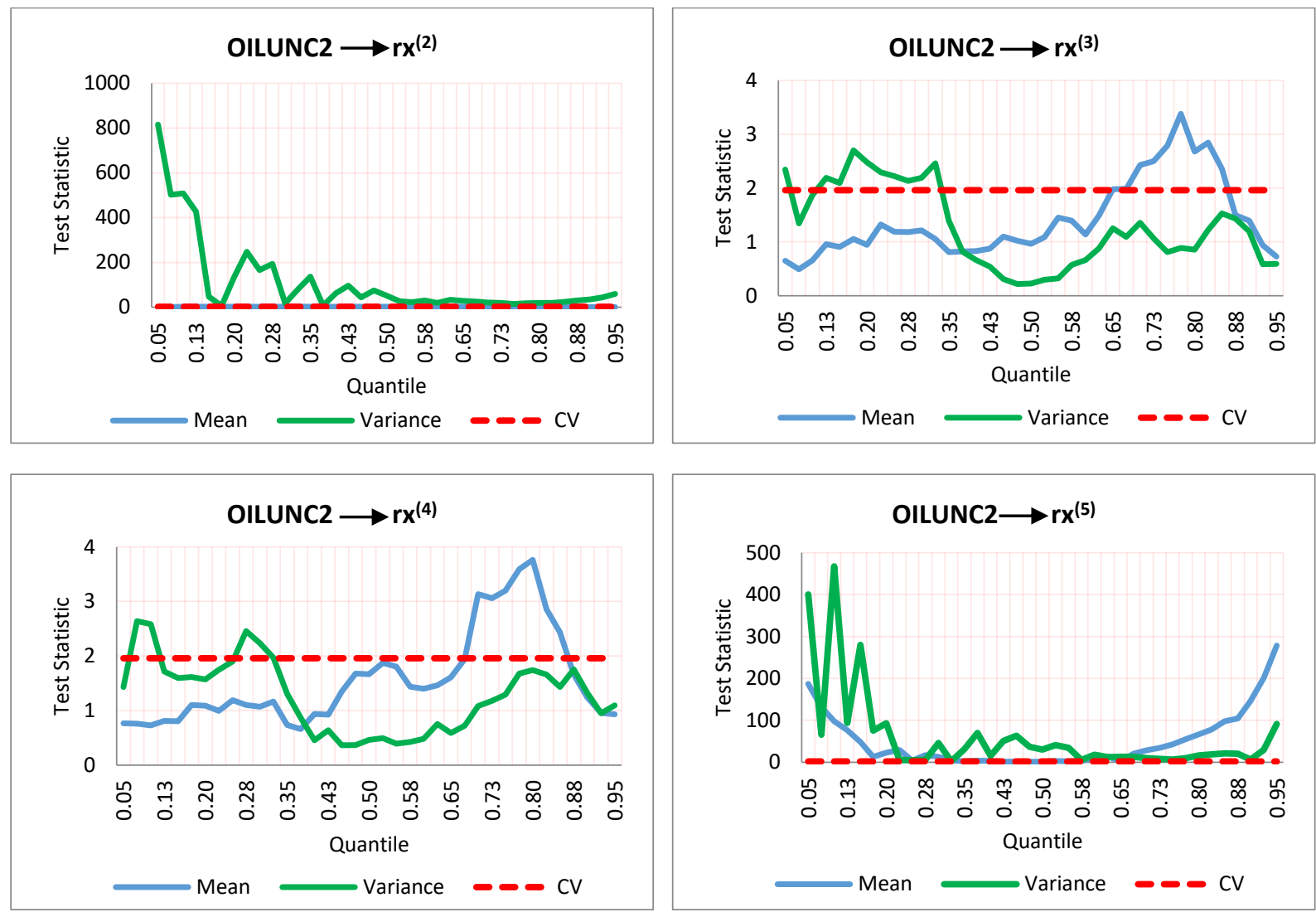

Figure B1(a). Causal Impact of TVP-SV Model-Based Oil Uncertainty (OILUNC2) on Bond Premium and Volatility
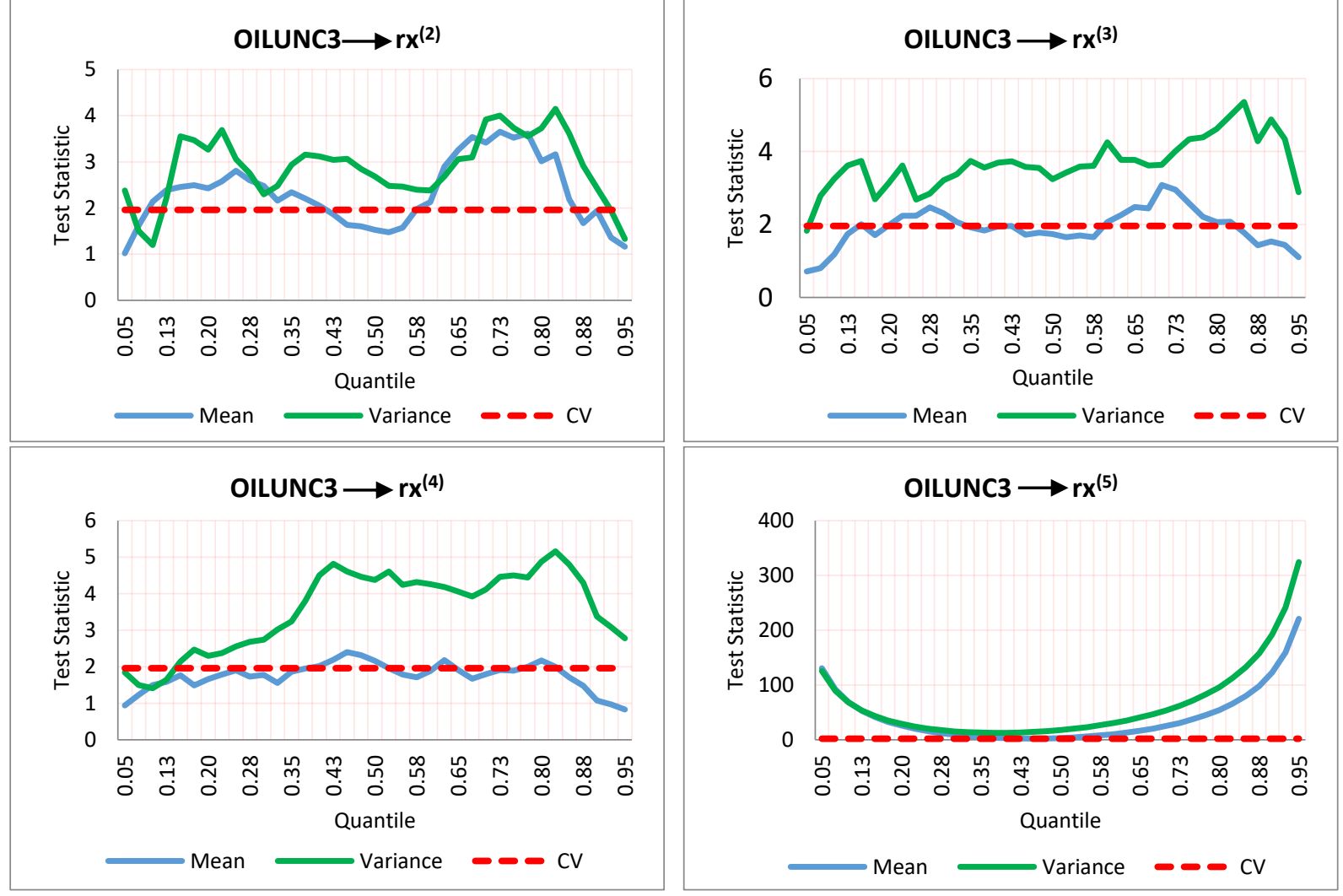

Figure B1(b). Causal Impact of RV-Based Oil Uncertainty (OILUNC3) on Bond Premium and Volatility. 

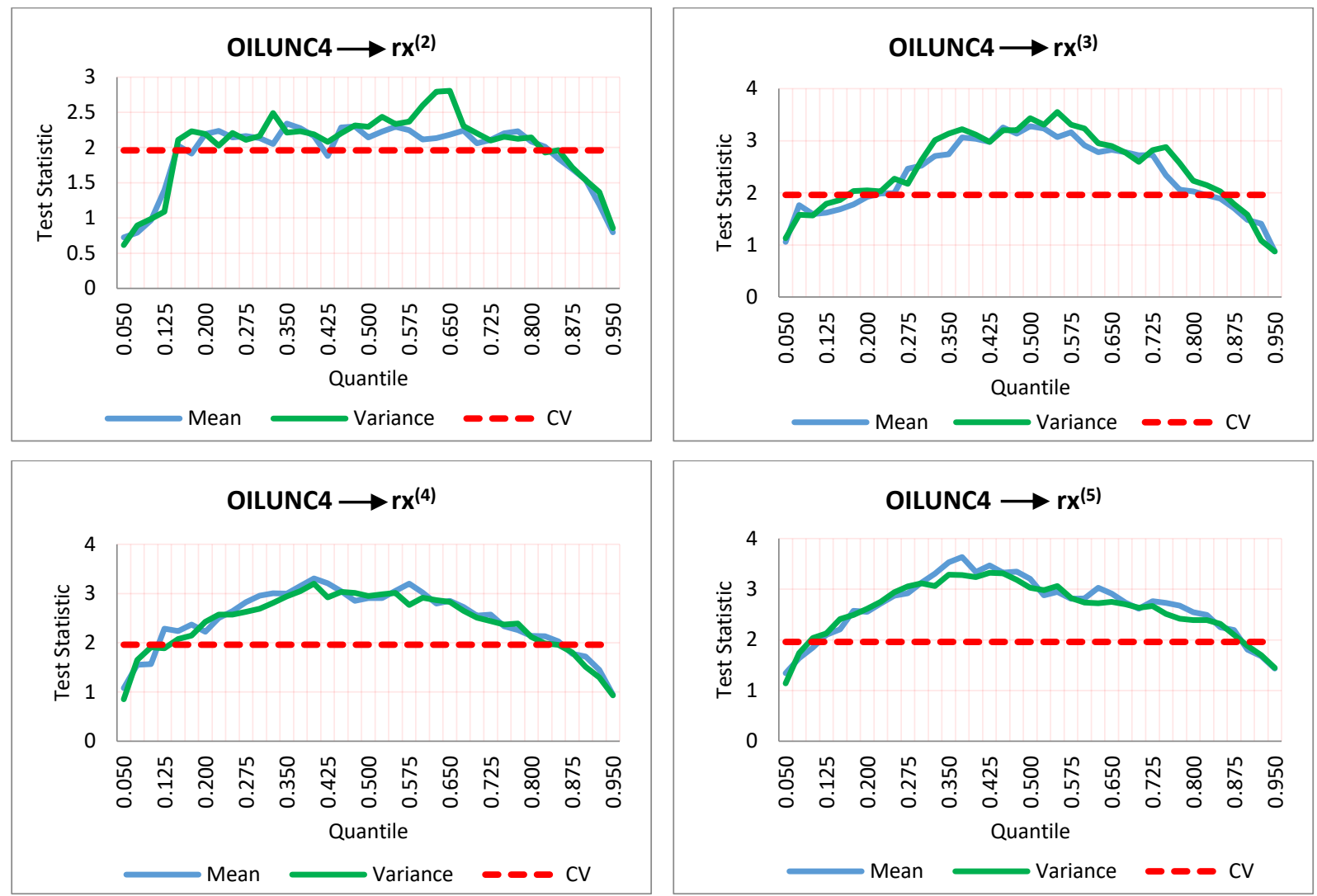

Figure B1(c). Causal Impact of Oil VIX (OILUNC4) on Bond Premium and Volatility Note: See Notes to Figure 1.

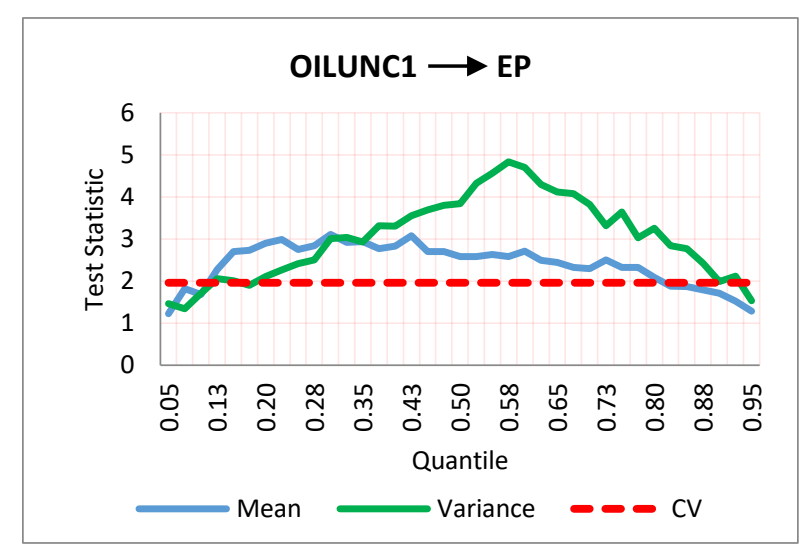

Figure B2. Causal Impact of GARCH $(1,1)$ Model-Based Oil Uncertainty (OILUNC1) on Equity Premium (EP) and Volatility 


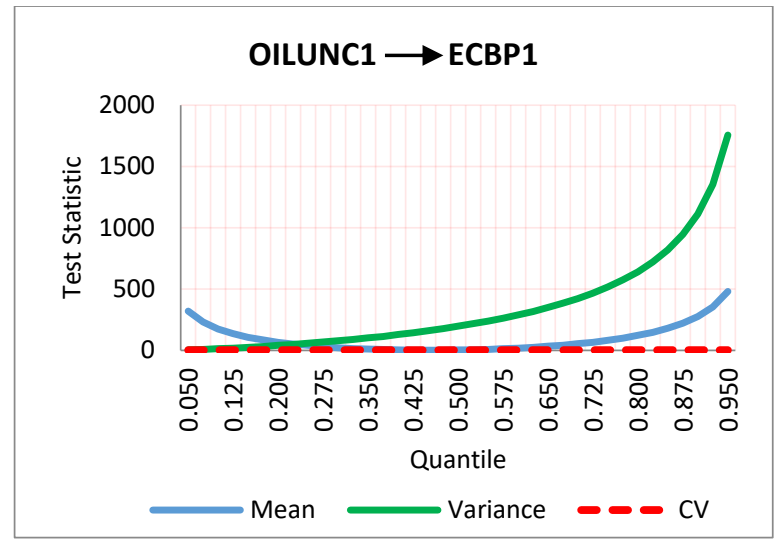

Figure B3. Causal Impact of GARCH $(1,1)$ Model-Based Oil Uncertainty (OILUNC1) on Corporate Bond Premium (ECBP) and Volatility

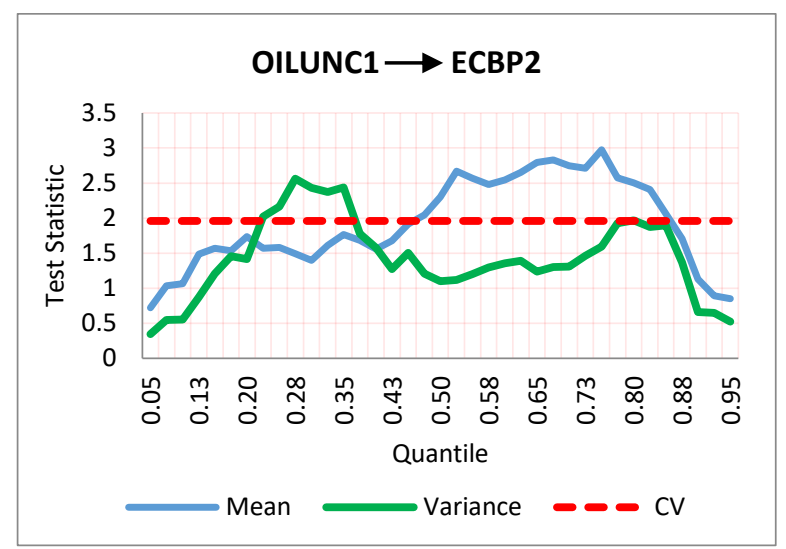

Figure B4. Causal Impact of GARCH $(1,1)$ Model-Based Oil Uncertainty (OILUN1) on an Alternative Measure of Corporate Bond Premium (ECBP2) and Volatility

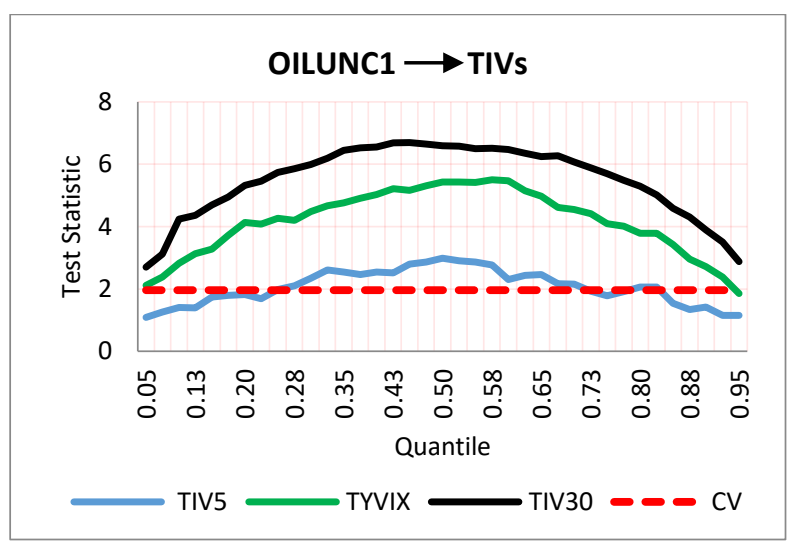

Figure B5. Causal Impact of GARCH $(1,1)$ Model-Based Oil Uncertainty (OILUNC1) on Implied Volatility of US Treasury Bonds (TIV)

Note: TIV5, TYVIX, TIV30 corresponds to maturities of 5-, 10-, and 30-year. 